ISSN 1981-416X

Licenciado sob uma Licença Creative Commons

\title{
O movimento de transição da Educação Rural para Educação do Campo: contradições e tensionamentos
}

\section{The transition movement from Rural Education to Education in the Field: contradictions and tensions}

\author{
Silvana Cassia Hoeller ${ }^{[a][b]}$, Maria Elisabeth Blanck Miguel ${ }^{[a]^{*}}$ \\ [a] Pontifícia Universidade Católica do Paraná (PUCPR), Curitiba, PR, Brasil \\ [b] Universidade Federal do Paraná (UFPR), Curitiba, PR, Brasil
}

\section{Resumo}

Este artigo tem por objetivo apresentar o movimento de transição da Educação Rural para a Educação do Campo, por meio do estado da arte acerca das pesquisas sobre as políticas públicas para a Educação do Campo publicadas entre os anos de 1996 a 2017 na área de conhecimento da Educação, buscando os históricos de produção e as contradições e tensionamentos presentes. Para efetuar essa busca, utilizamos como fontes as produções depositadas no repositório da Coordenação de Aperfeiçoamento de Pessoal de Nível Superior (CAPES) e na base de dados da Biblioteca Digital Brasileira de Teses e Dissertações (BDTD). Para isto, elegemos as palavras de busca: PROCAMPO, PRONACAMPO, PRONERA, Educação do Campo, e políticas para o rural. A escolha do período histórico ao qual delimitamos esta pesquisa assume como ponto de partida os primeiros grandes eventos em nível nacional a abordar as políticas para a Educação do Campo: a promulgação da LDB 9.394/96 e o Encontro 
Nacional de Educadores e Educadoras do Campo (ENERA) ocorrido em 1997. Os documentos oficiais - como a LDB (1996), as Diretrizes Operacionais por uma Educação Básica do Campo (2002) e o Decreto no 7.352 de 04 de novembro de 2010 - representam fontes presentes nas pesquisas que discutem a implementação e gestão das políticas públicas para a Educação do Campo. Assim, também destacamos que as pesquisas produzidas sobre políticas públicas para a Educação do Campo se concentram em maior número a partir de 2009 até a atualidade. Como principais resultados, identificamos que as demandas apresentadas pelos movimentos sociais foram consideradas em pesquisas acadêmicas (teses e dissertações), como também fortaleceram a Educação do Campo, na área de conhecimento da Educação, e traduziram as contradições e tensionamentos presentes na questão.

Palavras-chave: Educação do Campo. Educação Rural. Movimentos de transição. Tensionamentos e contradições.

\section{Abstract}

This article aims to present the transition, in Brazil, from the Rural Education paradigm to the Education in the Field paradigm, using state-of-the-art studies on the public policies geared toward Education in the Field published between 1996 and 2017 in the field of Education, while researching their production histories, and their contradictions and tensions. To do so, we used as sources the studies archived in the databases of the Coordenação de Aperfeiçoamento de Pessoal de Nível Superior (CAPES, Coordination of Improvement of Higher Level Personnel) and the Biblioteca Digital Brasileira de Teses e Dissertações (BDTD, Brazilian Digital Library of Dissertations and Theses). Furthermore, we searched for the following keywords: PROCAMPO, PRONACAMPO, PRONERA, Education in the Field, and rural policies. Our choice of the historical period on which we focused this study has as a starting point the first large-scale, nationwide events to approach the subject of Education in the Field policies: the promulgation of the LDB 9394/96 and the Encontro Nacional de Educadores e Educadoras do Campo (ENERA, National Meeting of Educators of the Field) of 1997. Official documents - such as the LDB (1996), the Diretrizes Operacionais por uma Educação Básica do Campo (Operational Guidelines for a Basic Education in the Field) (2002) and Decree 7.352 of November 4, 2010 - constitute sources which are present 
in the studies discussing the implementation and management of the public policies for Education in the Field. Thus, we also stress that the research on Education in the Field public policies were produced in greater numbers from 2009 to this day. As the main results of this study, we found that the demands presented by related social movements were researched by academic works such as dissertations and theses, and that these demands fostered the Education in the Field paradigm in the broader subject of Education, and translated the contradictions and tensions inserted in this context.

Keywords: Education in the Field. Rural Education. Paradigm change. Tensions and contradictions.

\section{Introdução}

Com o objetivo de apresentar o movimento de transição da Educação Rural para a Educação do Campo, buscando os históricos de produção, as contradições e os tensionamentos presentes, apresentamos neste artigo, o resultado do processo de imersão que realizamos nas pesquisas publicadas entre os anos de 1996 a 2017, na área de Educação, acerca do referido tema. Buscamos nelas elementos para a constituição de um quadro referencial dos conhecimentos até então sistematizados nas universidades e espaços científicos. Na delimitação do processo de transição entre a Educação Rural e Educação do Campo, com a intencionalidade de compreender se as políticas públicas acompanhavam este caminho, além da área de conhecimento da Educação, ampliamos a busca para as produções nas Ciências Humanas.

A escolha do tempo histórico ao qual delimitamos esta pesquisa privilegia como ponto de partida os primeiros grandes eventos em nível nacional: a promulgação da LDB 9.394/96 e o Encontro Nacional de Educadores e Educadoras do Campo (ENERA) ocorrido em 1997. A maior importância do ENERA está no fato de ter reunido os anseios dos educadores, educadoras e militantes da educação do campo que vinham - juntamente com os movimentos sociais - buscando o reconhecimento e a consolidação do direito 
à educação dos camponeses. No ano seguinte, o grupo que se originou do I ENERA organizou e articulou, em 1998, a I Conferência Nacional por uma Educação Básica do Campo (I CNE), cujo resultado foi o Programa Nacional de Educação na Reforma Agrária, PRONERA ${ }^{1}$. Este demarcou, de modo significativo, a consolidação da luta e acesso dos camponeses à educação.

Para dar resposta à demanda materializada pelos movimentos sociais, em 2002, o governo aprovou as Diretrizes Operacionais para a Educação Básica nas Escolas do Campo. Consideradas um salto para consolidação da Educação do Campo do Estado, as Diretrizes trazem delimitações e conceitos que até o momento estavam apenas nas reivindicações dos movimentos sociais, como, por exemplo, a identidade da escola do campo (BRASIL, 2002, p. 1).

Este breve histórico tem a intenção de mostrar que a produção do conhecimento na área de Educação do Campo - produção essa depositada no repositório da Coordenação de Aperfeiçoamento de Pessoal de Nível Superior (CAPES) e na base de dados da Biblioteca Digital Brasileira de Teses e Dissertação (BDTD) - é demarcada por duas fases: a primeira com o termo Educação Rural; e a segunda fase com o termo Educação do Campo. Cabe aqui perceber a distinção entre educação rural e educação do campo. Segundo Werthein e Bordenave (1981, p. 34), “[...] a educação rural tende a ser meramente uma projeção da educação urbana fora das cidades, sem nenhuma tentativa de adequação às sociedades rurais." A Escola Rural procura formar grupos semelhantes aos que vivem na cidade, separando-os de sua cultura e dos valores da comunidade de pertencimento. Este conceito é corroborado por Arroyo (2007), que traz o processo da idealização do espaço urbano como civilização e a escola rural como extensão da cidade.

A Resolução CNE/CEB nº 01 de 2002, que institui as Diretrizes Operacionais para Educação Básica das Escolas do Campo, resultado das reivindicações dos movimentos sociais, reafirmada na I Conferência

1 Programa Nacional de Educação na Reforma Agrária, o PRONERA tem o objetivo de fortalecer a Educação nos Projetos de Assentamento de Reforma Agrária, utilizando metodologias específicas para o campo, que contribuam para o desenvolvimento rural sustentável dos Projetos de Assentamento (Portaria ${ }^{\circ}$ 10, de 16 de abril de 1998. Publicada no DOU no 77, de 24/04/1998 e no Boletim de Serviço no 17, de 27/04/1998). 
Nacional por uma Educação Básica do Campo em 1998, reconhece que há um "[...] modo próprio de vida social e de utilização dos espaços do campo como fundamentais, em sua diversidade, para constituição da identidade da população rural e de sua inserção cidadã na definição dos rumos da sociedade brasileira". Esta mesma resolução, no parágrafo único do artigo 02, explicita a identidade da escola do campo e por consequência, a educação que dela deve emanar, ou seja, uma educação vinculada às questões da sua realidade, tendo como referências seu tempo histórico e os conhecimentos próprios dos estudantes (BRASIL, 2002).

Destacamos que essa fase de transição faz parte de um processo em movimento. Por isso, apesar de o termo Educação Rural ainda ser utilizado até os dias atuais, um número significativo de produções com o termo Educação do Campo tem-se sobressaído e vem se consolidando no espaço acadêmico em contraposição ao da Educação Rural.

Para início das discussões sobre o estado da arte das políticas públicas em Educação do Campo, necessitamos buscar essa transição da Educação Rural para Educação do Campo nas pesquisas produzidas. A partir dessa delimitação, pretendemos chegar à essência da produção desses trabalhos com o foco nas políticas públicas.

A partir do início do período escolhido para a realização do estudo, tivemos como objetivo mapear as produções acadêmicas sobre as políticas públicas vinculadas à Educação do Campo. Para refinar a busca, o intervalo de data foi selecionado com base em alguns aspectos. O primeiro deles foi a Lei de Diretrizes e Bases da Educação Nacional (LDB), que, ao ser aprovada, trouxe especificidades da educação rural.

Além da LDB esse tempo histórico também é caracterizado por contradições e tensionamentos que marcaram o cenário de construção de políticas públicas educacionais de Estado como o que já foi destacado anteriormente. No início dos anos 1990, no cenário internacional, para sair da crise dos anos 1980, foram implementadas transformações rumo ao estado mínimo, sob a égide do neoliberalismo. Nesse mesmo período, a UNESCO realizou a Conferência Mundial de Educação para todos, que ficou conhecida como a Conferência de Jomtien, a qual propunha um projeto de educação 
internacional, com a meta de universalização da educação básica, como possibilidade de modificar a conduta de jovens e adultos, com impactos na saúde, no emprego e na produtividade (SHIROMA; MORAES; EVANGELISTA, 2002). Nessa mesma década de 1990, com intencionalidade distinta dos pressupostos da Conferência de Jomtien, no Brasil, acontecia o I ENERA (1997), a I CNE (1998) e a instalação do PRONERA (1998), seguido, em 2002, pela aprovação das Diretrizes Operacionais para a Educação Básica da Escola do Campo (BRASIL, 2002). Estas datas permitem perceber a delimitação de 1996 a 2004 como sendo a primeira fase em que aparecem as produções de teses e dissertações que podem ser denominadas como transitórias da Educação Rural para Educação do Campo.

A segunda fase foi delimitada entre 2004 e 2017, momento em que a referência à Educação Rural passa a constar nos documentos oficiais e políticas públicas como Educação do Campo. Tais ocorrências podem ser verificadas na Resolução CNE/CEB n 01 de 2002 - diretrizes operacionais; Resolução ${ }^{\circ}$ 2, de 28 de abril de 2008, que estabelece normas para o desenvolvimento de políticas públicas para Educação do Campo; Decreto $n^{\circ}$ 7.352, de novembro de 2010 — PRONERA e a Educação do Campo; a alteração da LDB (1996) pela Lei 12.960 de 2014 — explicitando o termo escola do campo. Essa caminhada é explicitada nas produções acadêmicas. Assim, a partir desse período, é possível discutir o estado da arte das pesquisas em Políticas Públicas na Educação do Campo.

Para qualificar o estudo, elegemos descritores que pudessem trazer os elementos para a discussão da primeira e segunda fase, acima explicitadas. Dessa forma, na primeira fase, utilizamos dois descritores para a busca no banco de pesquisa: Educação Rural e Educação do Campo. Na segunda fase utilizamos os seguintes descritores para a busca: PROCAMPO², PRONACAMPO, PRONERA, Educação do Campo e

2 O objetivo do Programa de Apoio à Formação Superior e Licenciatura em Educação do Campo (PROCAMPO) é promover a formação de educadores para atuarem nas diferentes etapas e modalidades da educação básica dirigidas às populações que trabalhem e vivam no campo, pelo estímulo à criação, nas universidades públicas de todo país, de cursos regulares de Licenciatura em Educação do Campo (HENRIQUE et al., 2007, p. 45). 
Políticas e Políticas para o Rural. Esta última seleção intentou que cada descritor atingisse um período e estivesse vinculado ao tema das políticas públicas. Vale lembrar que, na segunda fase, o termo Educação do Campo ganhou força na produção do conhecimento, ou seja, nos trabalhos de pesquisa (teses e dissertações) a partir de 2005 até os dias atuais.

Na sequência dessa discussão, apresentamos elementos da transição da Educação Rural para a Educação do Campo, o estado da arte, seguido das considerações finais.

\section{A transição da Educação Rural para Educação do Campo}

Antes de discutirmos os elementos constituintes desta pesquisa, evidenciamos os estudos de Calazans, Castro e Silva (1981) e Damasceno e Beserra (2004). Estes autores pautam historicamente as contradições na Educação Rural e trazem a necessidade das especificidades do campo e consequentemente da Educação do Campo.

Os estudos realizados por Calazans, Castro e Silva (1981) trazem um levantamento e análise dos avanços e retrocessos das tentativas educacionais no meio rural de 1930 a 1980, principalmente as ofertadas por programas vinculados ao Estado. Esse trabalho foi um passo importante para expor a informação de que "a ação educativa implícita nos programas e projetos desenvolvidos nas áreas rurais do Brasil partem de uma falsa noção do que costuma chamar-se de 'atraso rural'" (CALAZANS; CASTRO; SILVA, 1981, p. 164). As teses e dissertações atuais resgatam esta noção do "atraso", como a crítica à Educação Rural.

As pesquisadoras Damasceno e Beserra (2004) mapearam e discutiram o conhecimento produzido na área da Educação Rural nas décadas de 1980 e 1990, com o objetivo de esboçar o "estado da arte" no campo da Educação Rural. As autoras trazem produções que focam dois grandes eixos: o primeiro, a precariedade da Educação Rural e a dificuldade em atender à Constituição de 1988; o segundo, a necessidade de uma escola do campo que atendesse a realidade dos sujeitos, apoiada pelos 
movimentos sociais que pressionaram a efetivação desse processo por meio de políticas públicas. Essa pressão dos movimentos sociais, a partir da década de 90, aparece traduzida em diversas pesquisas.

\section{O que revelam as pesquisas sobre a transição da Educação Rural para Educação do Campo}

Neste sentido, na primeira fase da busca (1996 a 2004), no catálogo da CAPES e da BDTD, encontramos 255 pesquisas que têm o termo "Educação Rural" e "Educação do Campo", selecionamos, dentro da área de conhecimento de Humanas, 60 pesquisas, sendo 8 de doutorado e 52 de mestrado. Fizemos nessa primeira etapa a leitura dos resumos. Para compreendermos o movimento das produções, elegemos uma categoria, denominada de "Transição da Educação Rural para Educação do Campo". A partir dela, criamos os seguintes indicadores: crítica à Educação Rural; experiências de educação em escolas rurais de assentamento; Educação do Campo em contraposição à Educação Rural; necessidade de políticas públicas de Educação do Campo. Os indicadores foram utilizados como instrumentos para a compreensão da categoria que fundamenta o tema em estudo, resultando na seleção de 14 pesquisas (12 dissertações e duas teses) que, a partir da leitura do trabalho completo, possibilitaram indicar elementos para discutir a categoria Transição da Educação Rural para Educação do Campo.

Ao olharmos esse conjunto de pesquisas produzidas de 1996 a 2004, identificamos uma forte crítica à concepção de Educação Rural, abordada nos temas apresentados pelas teses e dissertações que tratam da transição. Dentre elas destacam-se: urbanização do rural (LEITE, 1996); reprodutivismo da educação rural (REIS, 1999) e retrocessos do rural (BEZERRA, 1998). As críticas desses autores vêm ao encontro do trabalho de Calazans, Castro e Silva (1981), que chama atenção para o fato de o rural ser visto como um "complexo de carências" (p. 170), para o qual a educação vem no sentido de redenção. Isso nos ajuda a entender porque a Educação Rural carrega sinônimos de atraso. 
Encontramos também nove estudos focados na Pedagogia da Alternância entre 1996 e 2004, que, do total de 60, equivalem a 15\%. A alternância é compreendida como possibilidade para a demanda da diversidade do rural, de acordo com o que traz a LDB (BRASIL, 2017) em seu artigo 23, que prevê as muitas formas de organização escolar.

Ainda na busca de pesquisas que revelassem a transição da Educação Rural para a Educação do Campo, encontramos outras 15 (quinze) produções. Elas representam $25 \%$ das produções e tratam das experiências desenvolvidas pelo Movimento Sem Terra (MST) nas escolas localizadas em assentamentos, caracterizando o que chamamos anteriormente, de pressão dos movimentos sociais sobre a necessidade de educação básica no e do campo.

Essa intensificação de produção de pesquisas com assentamentos tem também sua fundamentação na instalação do PRONERA (1998) como política pública e é resultado da aprovação das Diretrizes Operacionais para a Educação Básica das Escolas do Campo em 2002, acompanhando as discussões que amadureciam entre Estado e movimentos sociais. Tais discussões podem ser verificadas no parágrafo único das diretrizes, no qual se destaca a identidade da escola do campo e seu vínculo com os movimentos sociais:

A identidade da escola do campo é definida pela sua vinculação às questões inerentes à sua realidade, ancorando-se na temporalidade e saberes próprios dos estudantes, na memória coletiva [...] (BRASIL, 2002, p. 1).

A questão da cultura local e sua relação com a Educação Rural representam $8 \%$ das produções acadêmicas. Temas como a formação de professores, multisseriação, projeto político-pedagógico, crítica à Educação Rural, assistencialismo das políticas públicas compõem o restante dos estudos.

3 A expressão "Educação no Campo" significa que o processo educacional deve ser realizado no local em que vivem as famílias ou a comunidade, enquanto a expressão "Educação do Campo" significa que o processo educacional deve ser construído com os sujeitos do campo, a partir da sua realidade (CALDART, 2010). 
$\mathrm{Na}$ totalidade dos 255 estudos acadêmicos, consideramos que, a exemplo da dissertação de Leite (1996), o que se destaca e percorre as produções é a crítica à Educação Rural, Mas também foram discutidos temas que envolvem a Pedagogia da Alternância e a diversidade cultural, atendendo o art. 28 da LDB 9.394/96, pois segundo este artigo:

Art. 28. Na oferta de educação básica para a população rural, os sistemas de ensino promoverão as adaptações necessárias à sua adequação às peculiaridades da vida rural e de cada região, especialmente: I - conteúdos curriculares e metodologias apropriadas às reais necessidades e interesses dos alunos da zona rural; II - organização escolar própria, incluindo adequação do calendário escolar às fases do ciclo agrícola e às condições climáticas; [...] (BRASIL, 2017).

Estas especificidades da Educação Rural aparecem nas pesquisas acadêmicas como na tese de doutorado de Capelo (2000), que discute a diversidade cultural no meio rural, até então escondida sob a cortina do "homogêneo".

Nas análises das dissertações e teses de vários autores, é recorrente o processo histórico que remonta ao Brasil Colônia e ao tempo de sua dependência econômica da coroa portuguesa, bem como a organização do modo de produção agrícola, cuja finalidade era a de atender as necessidades de Portugal. Nas obras de Calazans, Castro e Silva (1981) e Oliveira (2000), destaca-se a expressão "acirramento da contradição entre Capital e Trabalho", que percorre as pesquisas retratando o contexto no qual se desenvolveram as iniciativas da Educação Rural.

Já nas pesquisas sobre as experiências na área educacional do MST, surgem aspectos vinculados à pressão dos movimentos sociais por direitos à educação básica. Tais experiências estão presentes nas dissertações de Oliveira (2000), Sepúlveda (2000) e Diekow (2001). Oliveira (2000) analisam "a educação do movimento sem-terra".

Na dissertação de Rodrigues (1999), encontram-se os anúncios do espaço vivenciado naquele momento com a luta pela educação dos assentados; nela, o autor afirma que "neste espaço temporal analisado, são os próprios sujeitos camponeses que, pelas suas organizações, trazem 
a questão da educação escolar à condição de questão política, tanto para suas próprias organizações quanto para o Estado brasileiro" (SANTOS, 2009, p. 41). Este aspecto acima mencionado é retratado nas pesquisas acadêmicas e reforça a necessidade de pensar a política pública na Educação do Campo.

Verifica-se que, a partir de 2002, há o início do processo de estabilização do conceito "Educação do Campo". Os resultados no repositório da CAPES para este descritor apontam 11 publicações selecionadas de acordo com a categoria: quatro dissertações, com leitura completa. Dentre esses, Santana (2002) traz o PRONERA, no campo das políticas públicas, articulado a uma transição do termo Educação do Campo. Ainda encontramos o trabalho de Coelho (2003) abordando a questão da luta por uma Educação do e no Campo e também pelas políticas públicas educacionais. Percebe-se, no estudo desta autora, que os termos Educação Rural e Educação do Campo ainda são tomados como sinônimos.

No estudo de Carvalho (2003, p. 35), o conceito do termo Educação do Campo já aparece consolidado e traz consigo um processo histórico de luta e organização, conforme enfatizado pela autora: "A expressão Por uma educação do campo [...] diz respeito à luta popular pela ampliação, acesso, permanência e direito à escola pública e pela construção de uma escola que esteja no campo, mas que também seja do campo; [...]”. A autora também aborda a necessidade das políticas públicas associadas à Educação do Campo, dentro dessa nova intenção de educação para e com os sujeitos do campo, ao destacar que "O elemento novo desta afirmação, desta identidade é a associação da Educação do Campo, com lutas por políticas públicas, e políticas públicas com Reforma Agrária" (CARVALHO, 2003, p. 44).

As teses e dissertações que compõem o universo delimitado de produções que abordamos nesse estudo apresentam características em comum: transitam entre os termos Educação Rural e Educação do Campo. Tais características podem ser assim explicitadas: 1 . A transição dos termos acompanha o tempo histórico e é marcada pelas contradições que são apresentadas pelas pesquisas, entendendo o rural na concepção de atraso, assistencialismo das políticas públicas, falta de acesso à educação, urbanização do rural e insuficiência na formação docente. Ao mesmo tempo, esse mesmo espaço reúne 
a cultura e as diferenças, trabalha na perspectiva de alternância e incorpora novas experiências a partir de assentamentos da reforma agrária.

A dissertação de Cavalcante (2003) retrata esse movimento da contradição da escola rural, ao abordar o distanciamento dos conteúdos e dos livros didáticos da realidade do campo, bem como a dificuldade de acesso às séries finais do ensino fundamental e médio. Rocha (2003) complementa ao trazer a situação das professoras leigas da escola do campo (grifo nosso) e o termo escola do campo, abordado como sinônimo de escola rural. Ou seja, não há ainda no trabalho desses pesquisadores um conceito de Escola do Campo/ Educação do Campo. Compreende-se que o termo Educação do Campo na relação com a escola do campo está em construção, ancorando-se no texto preparatório da I CNE em 1998, abrindo a discussão dos princípios pedagógicos de uma escola do campo, acompanhado em 2002 pelo Seminário Nacional de Educação do Campo. Caldart (2004) traz a reflexão sobre a identidade da Educação do Campo; em 2004, mantém a continuidade do trabalho teórico com o tema "Escola do Campo em Movimento" (p. 87), ou seja, o debate, entre 2002 e 2004, está aflorado nos movimentos sociais. Diante desse processo, entende-se que a academia inicia uma caminhada do conhecimento, buscando relações entre a escola do campo, a educação do campo e seus sujeitos. Mais tarde, vai se explicitando o processo da transição de Educação Rural para Educação do e no Campo, quando é incorporada a influência da pressão dos movimentos sociais sobre o Estado. Esses tornam a situação visível para a sociedade, por meio de encontros, conferências e congressos, buscando políticas de acesso à educação para os camponeses.

Podemos entender que esse momento marca a consolidação da identidade da Educação do Campo, expressa em algumas produções, como na dissertação de Ribeiro (2003), cujo foco de pesquisa é uma turma de magistério na perspectiva do "semeando a Educação do Campo", e como em Coelho (2003), cuja dissertação integra as Diretrizes Operacionais para Educação Básica da Escola do Campo, buscando as relações com a LDB, colocando em evidência as particularidades da Educação do e no Campo, na perspectiva discutida pelos movimentos sociais. No entanto, ainda mantém Educação Rural como sinônimo de Educação do Campo, não fazendo uma distinção entre os dois conceitos; 
o processo está em construção nas produções acadêmicas. Finalmente, em um terceiro ponto, a Educação do Campo na perspectiva de luta e de projeto de povo consolida-se nas produções. Como bem afirma Caldart (2010, p. 39), trazendo a discussão das origens da Educação do Campo, esse movimento "[...] nasceu como crítica à realidade da educação brasileira, particularmente à situação educacional do povo brasileiro que trabalha e vive no/do campo". Avançando, na dissertação de Carvalho (2003), está explícita a relação da Educação do Campo com um novo projeto de escola e de reforma agrária em que os camponeses atuam como sujeitos. No contexto do estudo da autora, fica bem marcada a necessidade de uma política pública vinculada à realidade do campo.

Para o objeto que nos propomos a discutir neste artigo, é importante delimitar esta transição da Educação Rural para Educação do Campo; assim podemos compreender em que momento aparecem as políticas públicas de Educação do Campo na produção acadêmica.

Nesta segunda fase do trabalho, compreendemos que, delimitado o processo de transição da Educação Rural para Educação do Campo, podemos buscar o que foi produzido de pesquisas, entre teses e dissertações, no período de 2004 a 2017 no repositório da CAPES e na BDTD, considerando os seguintes descritores de busca: PROCAMPO, PRONACAMPO, PRONERA, Educação do Campo e Políticas e Políticas para o Rural. Acrescentamos que as pesquisas referentes aos descritores PROCAMPO surgem a partir de 2009 e o PRONACAMPO em 2014.

Em uma análise do período (1996 a 2017), podemos, antes de pautar algumas questões, observar que aparecem trabalhos no descritor de busca de "Políticas para o Rural" a partir de 1998. Esse é um elemento que mostra a transição das políticas da Educação Rural às políticas para Educação do Campo. Evidencia-se aí também o PRONERA, que se coloca neste espaço como o primeiro programa que relaciona a reforma agrária aos processos educacionais em assentamentos e acampamentos.

A dissertação de Molina (1998) centra no papel da reforma agrária nos anos noventa, explorando as divergências entre a proposta que considera a redistribuição fundiária somente como política social compensatória e a concepção que considera a reforma agrária como política 
econômica e social. Os debates que relacionam as políticas do rural fazem parte do processo de transição no qual a problemática da reforma agrária está presente pela pressão exercida pelos movimentos sociais, como podemos constatar no estudo da autora.

Da análise da dissertação da pesquisadora Holanda (2000), ao balizar pelo descritor PRONERA, é possível perceber que a autora faz um trabalho com estudantes do programa indicando identidade com os movimentos sociais; no entanto, ela não analisa o impacto do PRONERA como política pública para atender uma especificidade.

O descritor PRONERA, no universo de 149 pesquisas entre teses e dissertações da área de conhecimento Educação apenas no repositório da CAPES, representa 33\% do que foi produzido do ano de 1996 até o ano de 2017, totalizando 50 trabalhos que desenvolvem o estudo sobre o descritor. Retiramos os trabalhos que analisam aspectos que não têm essa relação, mas apenas a citação do Programa.

No descritor de busca Educação do Campo e Políticas, no período de 1996 até 2017 é possível encontrar grande número de produções a partir de 2008, intensificado em 2009. Torna-se possível afirmar que, com a consolidação da Educação do Campo e de suas políticas públicas, as pesquisas sobre o tema representam 82 trabalhos entre teses e dissertações, ou seja, 55\% do total de 149 estudos.

Já o Programa Nacional de Educação do Campo (PRONACAMPO) na área de Educação, apresenta quatro pesquisas produzidas a partir de 2014 e o Programa de Apoio à Formação Superior em Licenciatura em Educação do Campo (PROCAMPO) consta em oito estudos na área de Educação, com início em 2009. Observa-se que ambos os programas foram lançados pelo Estado em 2008 (oficialmente), mas os trabalhos só começam a ser produzidos com a denominação de Programa em 2013. 


\section{0 que revelam as pesquisas sobre a categoria estado da arte das Políticas Públicas em Educação do Campo}

Na categoria Estado da Arte das Políticas Públicas em Educação do Campo criamos os seguintes indicadores para compreender a imersão da pesquisa: "Transição das políticas públicas do rural para Educação do Campo"; "Políticas públicas voltadas à Educação do Campo na Relação com a Reforma Agrária"; "Políticas públicas para Educação do Campo".

Nessa encontramos, como texto completo, 18 pesquisas, sendo dez teses e oito dissertações, representando esse universo de estudos sobre políticas públicas para a Educação do Campo. A partir do recorte estabelecido, podemos discutir alguns pontos importantes da produção do conhecimento nesta área, o que nos dá subsídios para entender as mudanças que ocorreram na produção acadêmica durante um período histórico e as relações com o movimento das demandas das questões sociais.

No indicador que tem presente aspectos ligados à "Transição das Políticas do Rural para Educação do Campo" — já no ano de 1998 temos a dissertação de Molina, trazendo a reforma agrária como uma política que precisa ser verdadeiramente efetivada, mas aliando-se a outras iniciativas de educação. Em 2002, os estudos têm o foco no PRONERA como política de educação para o rural nas áreas de reforma agrária.

Logo em seguida, observamos que as produções ligadas à categoria "Políticas públicas voltadas à Educação do Campo na relação com a reforma agrária" têm como tema central as iniciativas educacionais provenientes da política pública do PRONERA. Há ainda uma vasta produção de trabalhos acadêmicos que buscam entender a relação movimentos sociais-gestão da política pública-Estado. Este aspecto pode ser confirmado também na tese de Albuquerque (2011, p. 71) que, no capítulo I, trata da produção do conhecimento (teses e dissertações) sobre a Educação no Campo do Brasil, totalizando 150 trabalhos com a expressão "Educação do e (no) Campo" publicados entre 2000 e 2009. Observamos que a autora contabiliza todas as áreas de conhecimento da CAPES e também aponta nas publicações a crítica à Educação Rural. Neste sentido, Albuquerque, reconhece que a produção do 
conhecimento, "[...] delimita os projetos históricos que estão sendo construídos por oposição, que determinam a produção científica, a qual contribui para impulsionar dialeticamente e legitimar determinadas posições de classe”.

Os temas abordados nas pesquisas das teses e dissertações que estão representadas na categoria "Estado da arte das políticas públicas em Educação do Campo" envolvem: formação docente, financiamento da educação, perspectivas culturais, relação com aprendizagem, direito à educação, relação capital e trabalho e Estado e movimentos sociais. Neste sentido, as produções durante o período pesquisado trazem elementos para a discussão de como os sujeitos do campo se inseriram e atuaram nas políticas públicas. Tratam também da forma como a pressão dos movimentos sociais possibilitou o acesso às políticas educacionais, bem como como se dá a relação do movimento de funcionamento do Estado na articulação com os sujeitos do campo e suas organizações.

Para a pesquisa, interessam recolher, de cada um dos passos desta trajetória, as questões pertinentes à instituição de políticas públicas; especialmente, políticas públicas relacionadas à formação de educadores, intituladas PROCAMPO e PRONACAMPO.

Com intuito de chegar a este refinamento, selecionamos os estudos que trazem elementos do estado da arte destas políticas de formação de educadores que fazem parte das políticas públicas intituladas PROCAMPO e PRONACAMPO. Podemos dizer que o estudo de Santos (2009) é um dos primeiros ensaios sobre o PROCAMPO, pois problematiza a nova proposta de formação de educadores e educadoras do campo, que consta das Diretrizes Operacionais (BRASIL, 2002).

A autora analisa o protagonismo dos movimentos sociais na sustentação do PROCAMPO na sua institucionalidade como política pública, frente ao Estado e nas instituições de Ensino Superior (IES). Além da legitimação do PROCAMPO como política pública, no estudo ficam abertos vários questionamentos que não são explorados pela pesquisa, como a absorção deste profissional licenciado em Educação do Campo pelas escolas ou em outras áreas afins. 
O estudo de Rocha (2013) analisa a trajetória das quatro universidades piloto que ofertaram a Licenciatura em Educação do Campo (PROCAMPO). O autor identificou, nesse processo, alguns avanços e algumas resistências dentro do espaço institucional. Rocha também buscou, nas instituições de ensino superior, os critérios para receber a política pública PROCAMPO.

Brito (2017), na pesquisa do doutorado, faz uma análise da Licenciatura em Educação do Campo da Universidade de Brasília como sendo uma das primeiras experiências de formação de educadores e educadoras nesta área, desde 2007. Neste estudo, Brito traz elementos importantes para o universo da discussão das políticas públicas, como a inserção do curso na realidade local, a participação política de educadores e educandos nas lutas regionais e o contexto em que se desenvolve o projeto político-pedagógico.

Menezes (2013) analisa dois programas de formação de professores voltados para a formação superior, PRONERA e PROCAMPO, a partir da realidade do Maranhão, trazendo como última análise a necessidade de se implantarem políticas públicas que respeitem e valorizem a Educação do Campo, considerem as questões relativas ao meio ambiente, respeitem o contexto sociocultural e a diversidade cultural.

Já Rotta (2017) associa a experiência do PROCAMPO na relação da posse da terra com os ideais pedagógicos do curso de licenciatura em Educação do Campo. O estudo de doutoramento da pesquisadora também nos dá pistas da complexidade das relações que envolvem as políticas públicas para Educação do Campo demandadas pelos movimentos sociais. Nas quatro (uma tese e três dissertações) pesquisas sobre o descritor PRONACAMPO, verificamos as contradições entre as reivindicações e os princípios dos movimentos sociais com a proposta do programa; essa relação se apresenta como um foco de desenvolvimento dos trabalhos, que pode identificado em Moraes (2014).

\section{Conclusões provisórias}

A leitura do estado da arte das pesquisas sobre Políticas públicas para Educação do Campo disponíveis no banco da CAPES e da BDTB 
procurou identificar o momento em que se evidencia o processo de transição da Educação Rural para Educação do Campo. Com isso foi possível compreender que este movimento foi gradual e acompanhado por questões históricas que envolvem a luta por reforma agrária, a crítica à Educação Rural, a necessidade de educação aos povos do campo e a relação instituída entre Estado e movimentos sociais.

Neste processo, delimitamos uma faixa de transição em movimento, que traz uma analogia, como um processo de mudança linguística que consiste na alteração de um termo, para adaptá-la a um modelo pré-existente, no caso da Educação Rural para Educação do Campo. Tal mudança também pode ser percebida como uma mudança gradual de conceito e compreensão de um espaço político em construção, trazendo no seu âmago contradições e tensionamentos. Podemos também acrescentar que as demandas apresentadas pelos movimentos sociais por meio do I ENERA (1997), I CNE (1998) e II CNE (2004) refletiram-se nas pesquisas acadêmicas e também fortaleceram a Educação do Campo como foco central de muitas teses e dissertações, principalmente na área da educação.

Destacamos, em um segundo momento, as pesquisas produzidas sobre políticas públicas para a Educação do Campo que - no período de maior produção desta temática - concentra-se de 2009 até a atualidade. Alcançamos um quadro que permite afirmar ser este um tema estimulador de produções acadêmicas. Dentro da área das políticas públicas, o PRONERA e o PROCAMPO têm um destaque em comum: ambos têm natureza educacional.

\section{Referências}

ALBUQUERQUE, J. de O. Crítica à produção do conhecimento sobre a educação do campo no Brasil: teses e antíteses sobre a educação dos trabalhadores no campo no início do século XXI. 2011. 186 f. Tese (Doutorado em Educação) - Universidade Estadual de Campinas, Campinas, 2011. 
ARROYO, M. G. Políticas de formação de educadores(as) do campo. Caderno Cedes: educação do campo, Campinas, v. 27, n. 72, p. 157-176, maio/ago. 2007.

BEZERRA, N. L. Sem Terra Aprende e Ensina: um estudo sobre as práticas educativas e formativas do Movimento dos Trabalhadores Rurais Sem Terra - MST - 1979-1998. Dissertação (Mestrado em Educação) - Universidade Estadual de Campinas, Campinas, 1998.

BRASIL. Decreto ${ }^{\circ}$ 7.352, de 4 de novembro de 2010. Dispõe sobre a política de educação do campo e o Programa Nacional de Educação na Reforma Agrária PRONERA. Casa Civil, Brasília, DF, 2010.

BRASIL. Ministério da Educação. Conselho Nacional de Educação. Câmara de Educação Básica. Resolução n ${ }^{\circ} 2$, de 28 de abril de 2008. Disponível em: <http:// portal.mec.gov.br/arquivos/pdf/resolucao_2.pdf〉. Acesso em: 20 abr. 2016.

BRASIL. Ministério daEducação. Conselho Nacional deEducação. Parecern n 36, de12 de março de 2002. Diário Oficialda União, Brasília, DF,13 mar. 2002. Disponívelem: <http:// portal.mec.gov.br/index.php?option=com_docman\&view=download\&alias=11989pceb036-01-pdf\&category_slug=novembro-2012-pdf\&Itemid=30192>. Acesso em: 26 ago. 2018.

BRASIL. Senado Federal. LDB: Lei de Diretrizes e Bases da Educação Nacional. Brasília: Senado Federal, Coordenação de Edições Técnicas, 2017.

BRITO, M. M. B. Formação de professores na perspectiva da epistemologia da práxis: análise da atuação dos egressos do curso de licenciatura em Educação do Campo da Universidade de Brasília, 2017. 379 f. Tese (Doutorado em Educação) — Universidade de Brasília, Brasília, 2017.

CALAZANS, M. J. C.; CASTRO, L. F. M.; SILVA, H. R. S. Questões e contradições da educação rural no Brasil. In: WERTHEIN, J.; BORDENAVE, J. D. Educação rural no terceiro mundo. Rio de Janeiro: Paz e Terra, 1981. p. 161-223.

CALDART, R. S. Educação do campo: notas para uma análise de percurso. In: MOLINA, M. C. (Org.). Educação do Campo e Pesquisa II: questões para reflexão. Brasília: MDA/MEC, 2010. 
CALDART, R. S. A escola do campo em movimento. In: ARROYO, M. G.; CALDART, R. S.; MOLINA M. C (org.). Por uma Educação do Campo. Petrópolis: Vozes, 2004.

CAPELO, M. R. C. Educação, escola e diversidade cultural no meio rural de Londrina (PR): quando o presente reconta o passado. 2000. 296 f. Tese (Doutorado em Educação) - Universidade Estadual de Campinas, Campinas, 2000.

CARVALHO, M. S. Formação de professores frente às demandas dos movimentos sociais: indicações para a universidade necessária. 2003. 145 f. Dissertação (Mestrado em Educação) — Universidade Federal da Bahia, Salvador, 2003.

CAVALCANTE, R. L. A. A escola rural e seu professor no campo das vertentes. 2003. 289 f. Dissertação (Doutorado em Educação) — Pontifícia Universidade Católica do Rio de Janeiro, Rio de Janeiro, 2003.

COELHO, N. M. G. Uma escola pública para crianças e jovens no campo: desafios, perspectivas e repercussões da LDB nos assentamentos Chê Guevara (Itaberaí) e São Domingos (Morrinhos) em Goiás. 2003. 151 f. Dissertação (Mestrado em Educação) —Pontifícia Universidade Católica de Goiás, Goiânia, 2003.

DAMASCENO, M. N.; BESERRA, B. Estudos sobre Educação Rural no Brasil: estado da arte e perspectivas. Educação e Pesquisa, v. 30, n. 1, jan./abr. 2004.

DIEKOW, I. R. A educação no contexto histórico de um assentamento de reforma agrária no Rio Grande do Sul. 2001. 188 f. Dissertação (Mestrado em Educação) Universidade Federal de Pelotas, Pelotas, 2001.

HENRIQUE, R. et al. (Org.). Educação do Campo: diferenças mudando paradigmas. Cadernos SECAD. Brasília, 2007.

HOLANDA, M. I. M. A construção da identidade coletiva dos sem-terra: um estudo a partir do cotidiano dos alunos do PRONERA. 2000.163 f. Dissertação (Mestrado em Educação) — Universidade Federal Do Ceará, Fortaleza, 2000.

LEITE, S. C. Urbanização do Processo Escolar Rural. 1996. 248 f. Dissertação (Mestrado em Educação) — Universidade Federal de Uberlândia, Uberlândia, 1996. 
MENEZES, M. C. Políticas Educacionais do Campo: PRONERA e PROCAMPO no Maranhão. 2013. 244 f. Tese (Doutorado em Ciências Sociais) — Pontifícia Universidade Católica de São Paulo, São Paulo, 2013.

MOLINA, M. C. A Reforma Agrária e o Movimento dos Trabalhadores Rurais Sem Terra: reinvenção do futuro. Dissertação (Mestrado em Sociologia) — Universidade Estadual de Campinas, Campinas, 1998. Disponível em: <http://repositorio. unicamp.br/jspui/handle/REPOSIP/281280 >. Acesso em: 20 jul. 2017.

MORAES, V. Programa Nacional de Educação do Campo (PRONACAMPO): entre a pauta dos povos do campo e o decidido pelo Estado. 2014. 195 f. Dissertação (Mestrado em Educação) - Universidade Estadual do Centro-Oeste, Guarapuava, 2014.

OLIVEIRA, H. D. L. de. Atividades produtivas do campo, etnomatemática e a educação do movimento sem terra. 2000. 130 f. Dissertação (Mestrado em Educação) Universidade do Vale do Rio dos Sinos, São Leopoldo, 2000.

REIS, M. E. Análise do reprodutivíssimo na educação rural brasileira numa perspectiva histórica. 1999. 132 f. Dissertação (Mestrado em Educação) - Universidade Católica de Brasília, Brasília, 1999.

RIBEIRO, S. C. F. Semeando a Educação do Campo: a experiência da $1^{\mathrm{a}}$ Turma de Magistério Norte/Nordeste do MST. Elizabeth Teixeira. 2003. 120 f. Dissertação (Mestrado em Educação) — Universidade Federal da Paraíba, João Pessoa, 2003.

ROCHA, E. N. Das práticas educativas às políticas públicas: tramas e artimanhas pela educação do campo. 2013. 329 f. Tese (Doutorado em Educação) — Universidade de Brasília, Brasília, 2013.

ROCHA, S. H.X. Projeto Político-Pedagógico para a Escola do Campo: dialogando com Paulo Freire. 2003. 145 f. Dissertação (Mestrado em Educação) — Universidade Federal do Maranhão, São Luís, 2003.

RODRIGUES, M. F. Da Luta pela Educação à Educação na Luta: Memórias, Narrações e Projetos dos Assentados e Professores do M.S.T. Na Fazenda Giacometi. 1999. 168 f. Dissertação (Mestrado em Educação) - Universidade Federal Fluminense, Niterói, 1999. 
ROTTA, M. De Luta Histórica pela Posse da Terra ao Grito de uma Licenciatura para Formação de Educadores do Campo na Região Sudoeste do Paraná. 2017. 276 f. Tese (Doutorado em Educação) — Pontifícia Universidade Católica do Paraná, Curitiba, 2017.

SANTANA, D. M. A. de. Políticas para o meio rural: o Pronera no Tocantins. 2002. 165 f. Dissertação (Mestrado em Educação) - Universidade Federal de Goiás, Goiânia, 2002.

SANTOS, C. A. S. Educação do Campo e Políticas Públicas no Brasil. 2009. Dissertação (Mestrado em Educação) — Universidade de Brasília, Brasília, 2009.

SEPÚlVEDA, G. A. O Movimento Sem Terra e a educação. 2000. Dissertação (Mestrado em Sociologia Política) - Universidade Federal de Santa Catarina, Florianópolis, 2000. Disponível em: <http://repositorio.ufsc.br/xmlui/ handle/123456789/78404>. Acesso em: 20 ago. 2017.

SHIROMA, E. O.; MORAES, M. C. M.; EVANGELISTA, O. Política Educacional. Rio de Janeiro: DP\&A Editora. 2002.

WERTHEIN, J.; BORDENAVE, J. D. (org.). Educação Rural no Terceiro Mundo: experiências e novas alternativas. Rio de Janeiro: Paz e Terra, 1981.

Recebido: 17/09/2018

Received: 09/17/2018

Aprovado: 28/10/2018 Approved: 10/28/2018 